\title{
Seasonal Variability of Salt and Heat Diffusion off North Eastern Egyptian Continental Slope
}

\author{
Mohamed Salama Elsharkawy \\ National Institute of Oceanography and Fisheries, Physical Laboratory, Alexandria, Egypt
}

Email address:

Sharkawy70@gmail.com

To cite this article:

Mohamed Salama Elsharkawy. Seasonal Variability of Salt and Heat Diffusion off North Eastern Egyptian Continental Slope. International Journal of Environmental Monitoring and Analysis. Vol. 4, No. 3, 2016, pp. 110-114. doi: 10.11648/j.ijema.20160403.17

Received: May 17, 2016; Accepted: May 25, 2016; Published: June 7, 2016

\begin{abstract}
The vertical diffusion of salt and heat throughout the water column at two stations along the northern Egyptian continental slope has been investigated. Seasonal profiles of the vertical transport salt showed that generally a downward salt flux occurred throughout the water column; however, upward salt fluxes intermittently occurred in the sub surface layer at depths between $75 \mathrm{~m}-150 \mathrm{~m}$. Seasonal averages of salt flux ranged from a minimum of $-1.7 \times 10^{-11} \mathrm{~kg} \mathrm{~m}^{-2} \mathrm{~s}^{-1}$ directed

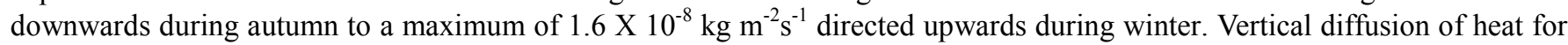
the four seasons has been found to be directed downwards throughout the whole water column. Estimates of seasonally averages of heat flux varied from a minimum of $-1.6 \times 10^{-5} \mathrm{~m}^{-2} \mathrm{~s}^{-1}$ attained during spring to a maximum of $-1.1 \times 10^{-2} \mathrm{~m}^{-2} \mathrm{~s}^{-1}$ attained during summer.
\end{abstract}

Keywords: Salt Diffusion, Heat Diffusion, Vertical Mixing

\section{Introduction}

The vertical transport of salt and heat has a key role in the dynamical processes of vertical mixing between water masses. The vertical turbulent mixing at the gulf of Cadiz, Libya was investigated by carrying out viscous dissipation and shear measurements [1]. The method of back scattering of high frequency acoustic waves has been utilized to measure the rate of viscous dissipation of turbulent kinetic energy [2].

Tidal currents are an important geophysical factor affecting the turbulent process of vertical mixing especially in coastal waters. The energetics of tidal mixing of was estimated to be about 3.7 TW mainly produced by M2. Most of that tidal energy is assumed to dissipate into the bottom boundaries of water basins [3]. The total dissipated energy of M2 was calculated at Seto Island, Japan to be about $3.4 \times 10^{9}$ $\mathrm{W}$ [4]. Measurements of velocity microstructure at Georges Bank, Canada confirmed that vertical turbulent mixing was primarily due to tidal stirring although atmospheric forcing played a significant role [5].

A semi-empirical model has been implemented to simulate the relative weight of various physical factors affecting vertical mixing: buoyancy, turbulence, shear, and viscous dissipation $[6,7]$. Parameters characterizing vertical turbulent mixing as dissipation, buoyancy, and Reynolds stress were studied along the Egyptian continental shelf. The study showed that the dynamical process of vertical mixing was stronger in winter and weakened with depth. Squared buoyancy frequency reached a maximum of $9.5 \times 10^{-4} \mathrm{~s}^{-2}$, viscous dissipation rate reached a maximum of $3 \times 10^{-9}$ W. $\mathrm{kg}^{-1}$, while Reynolds stress has a maximum of $1.1 \mathrm{X} 10^{-4}$ $\mathrm{Pa}$. All these three mixing parameters reached their greatest magnitude during winter [8].

\section{Data Availability}

The present study utilizes the readings collected by Fugro GEOS one year-long program (Feb-1999 to Feb 2000). A binding agreement between AMOCO, British Gas, I.E.O.C (International Egypt Oil Company) and the Belayim Petroleum Company (Petrobel) gave rise to the scientific program conducted by Fugro Geos. This survey was comprised of several stations along north eastern Egyptian 
continental slope with depths ranging from $8 \mathrm{~m}$ to $538 \mathrm{~m}$. The current was measured by acoustic Doppler current profilers (ADCP), while temperature and salinity, through the water column, were recorded by conductivity, temperature, depth profilers (CTD). The model of the CTD instrument used to collect the readings was SBE Sea cat Profiler V3.1b. Two stations have been selected to carry out the present investigation: station $\mathrm{A}(400 \mathrm{~m})$ located at $32^{\circ} 6.1^{\prime} \mathrm{N}, 32^{\circ} 0.3^{\prime} \mathrm{E}$, and station $\mathrm{B}(100 \mathrm{~m})$ located at $31^{\circ} 55.2^{\prime} \mathrm{N}, 32^{\circ} 0.7^{\prime} \mathrm{E}$. These two stations were chosen because they have best data quality, particularly longest series of continuous readings. The discontinuity of measurements resulted from technical malfunction, battery failure or any other cause of data loss. Hourly measurements have been averaged over the months of May, August, October, and January to represent seasonal averages which were subject to the present analysis.

\section{Seasonal Profiles of DSF}

The vertical transport of salt, alternatively, diffusive salt flux is a dynamical mixing parameter defined by:

$$
J_{s}=-10^{-3} \rho K_{s} \frac{\partial S}{\partial z}
$$

where $\rho$ is the sea water density, $S$ the salinity of the sea water, $z$ the depth, and $K_{s}$ is the Eddy coefficient of diffusivity which is related to viscous rate of kinetic energy dissipation $(\varepsilon)$, and buoyancy frequency $(N)$, mixing efficiency $(\Gamma)$ by the equation:

$$
K_{s}=\Gamma \frac{\epsilon}{N^{2}}
$$

in the present study $(\Gamma)$ has been set to $0.2[9,10]$.

The DSF attained a seasonal minimum of $-1.7 \times 10^{-11} \mathrm{~kg}$ $\mathrm{m}^{-2} \mathrm{~s}^{-1}$ directed downwards at station A during autumn. The maximum seasonal estimates were $1.6 \times 10^{-8} \mathrm{~kg} \mathrm{~m}^{-2} \mathrm{~s}^{-1}$ directed upwards at station A also during winter. Station B experienced relatively high estimates of DSF through the four seasons. Generally, the seasonal averaged estimates of DSF at station A were negative, i.e., a downward salt flux occurred, however, positive estimates of DSF were observed mainly in the sub surface layer of depth 75 m- $150 \mathrm{~m}$. Station B showed a different profile of DSF as upward and downward fluxes occurred intermittently throughout the four seasons. Profiles of seasonally averaged estimates of DSF are depicted in figures (1-8), and its basic statistics are presented in table 1.

Table 1. Seasonal vertically averaged estimates of diffusive salt flux $\left(\mathrm{kg} \mathrm{m}^{-2}\right.$ $\left.s^{-1}\right)$.

\begin{tabular}{llllll}
\hline & & spring & summer & autumn & winter \\
\hline \multirow{2}{*}{ Min } & St. A $(400 \mathrm{~m})$ & $-2.6 \mathrm{E}-10$ & $-2.1 \mathrm{E}-09$ & $-1.7 \mathrm{E}-11$ & $-4.9 \mathrm{E}-10$ \\
& St. B $(100 \mathrm{~m})$ & $-6.0 \mathrm{E}-10$ & $-1.1 \mathrm{E}-09$ & $-6.5 \mathrm{E}-11$ & $-4.1 \mathrm{E}-10$ \\
\multirow{3}{*}{ Max } & St. A $(400 \mathrm{~m})$ & $3.5 \mathrm{E}-09$ & $8.5 \mathrm{E}-11$ & $2.4 \mathrm{E}-11$ & $1.6 \mathrm{E}-08$ \\
& St. B $(100 \mathrm{~m})$ & $2.4 \mathrm{E}-09$ & $1.8 \mathrm{E}-10$ & $3.6 \mathrm{E}-09$ & $4.0 \mathrm{E}-11$ \\
& St. A $(400 \mathrm{~m})$ & $3.0 \mathrm{E}-10$ & $-3.6 \mathrm{E}-10$ & $3.8 \mathrm{E}-12$ & $1.4 \mathrm{E}-09$ \\
& St. B $(100 \mathrm{~m})$ & $4.4 \mathrm{E}-10$ & $-3.5 \mathrm{E}-10$ & $7.5 \mathrm{E}-10$ & $-7.9 \mathrm{E}-11$ \\
\hline
\end{tabular}

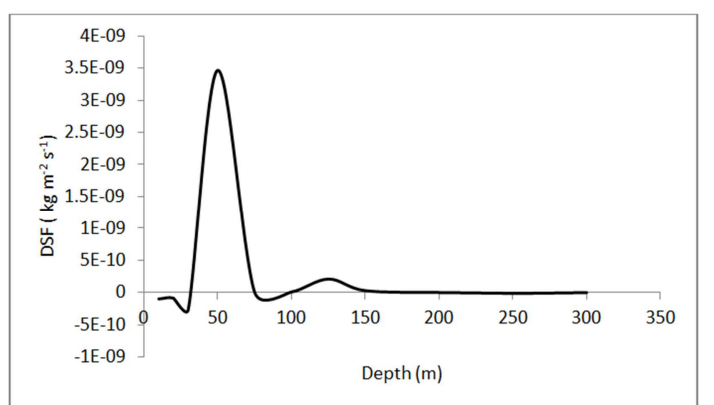

Fig. 1. Vertical distribution of salt flux during spring at station A.

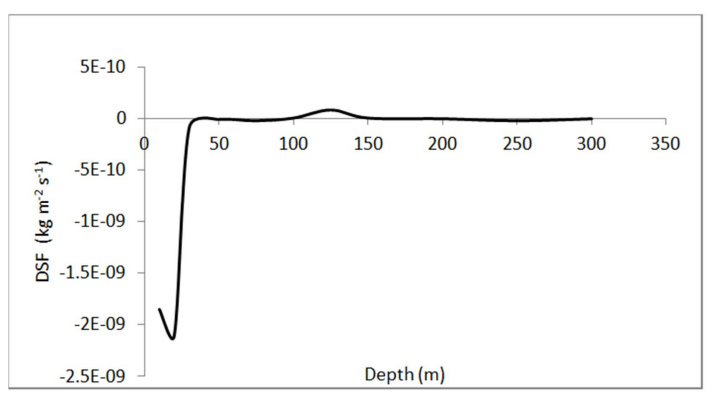

Fig. 2. Vertical distribution of salt flux during summer at station A.

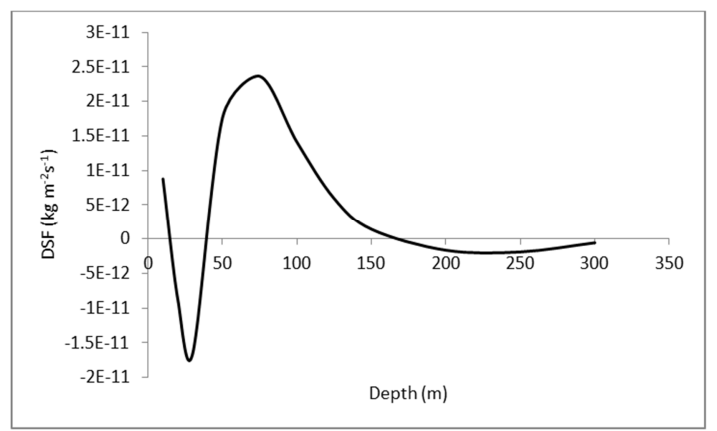

Fig. 3. Vertical distribution of salt flux during autumn at station A.

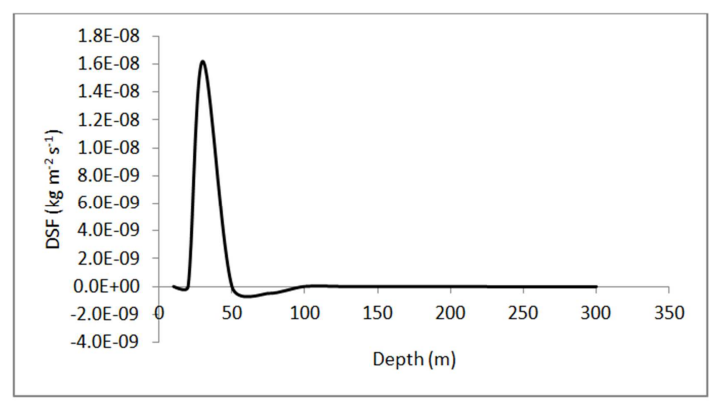

Fig. 4. Vertical distribution of salt flux during winter at station A.

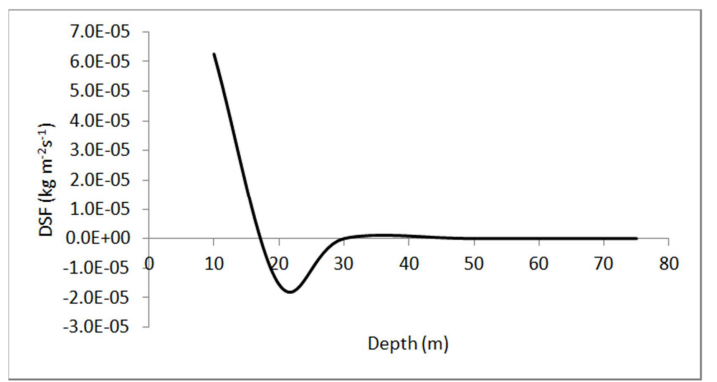

Fig. 5. Vertical distribution of salt flux during spring at station $B$. 


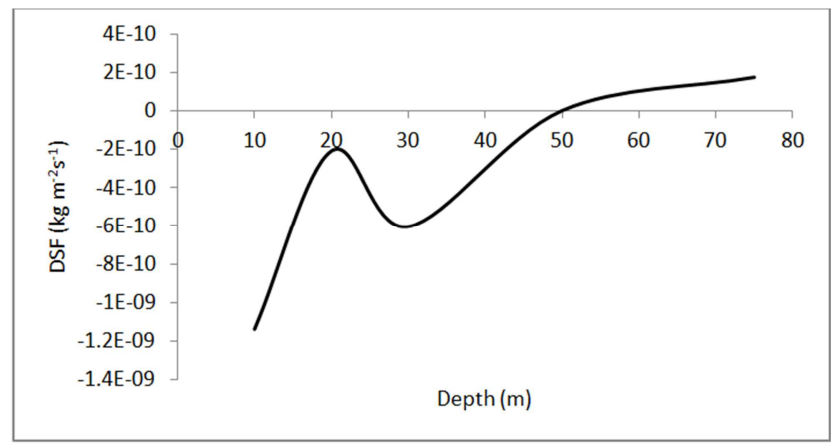

Fig. 6. Vertical distribution of salt flux during summer at station $B$.

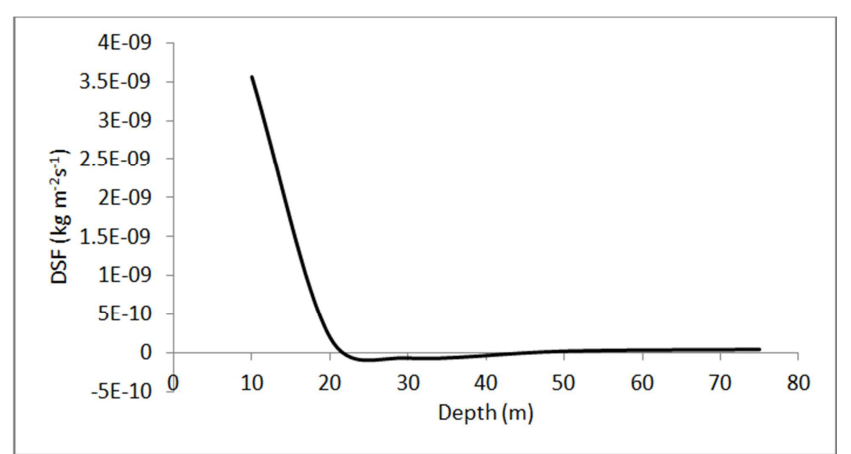

Fig. 7. Vertical distribution of salt flux during autumn at station B.

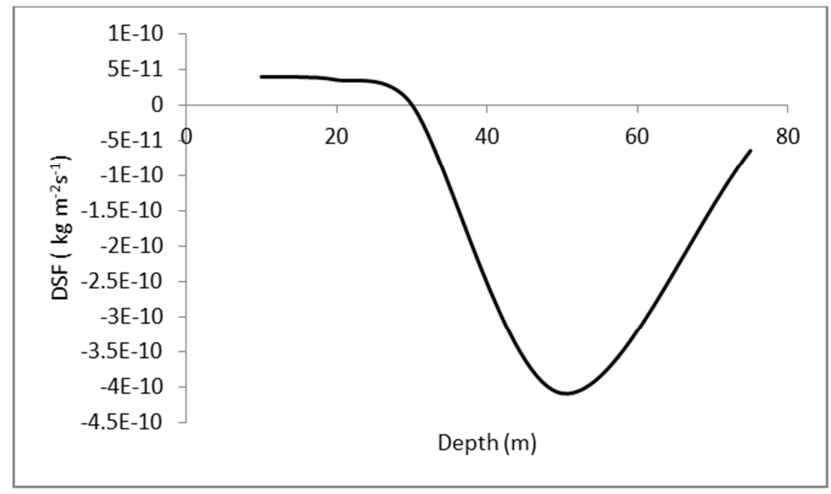

Fig. 8. Vertical distribution of salt flux during winter at station $B$.

\section{Seasonal Profiles of DHF}

The vertical transport of heat, alternatively, diffusive heat flux is also a dynamical mixing parameter defined by:

$$
J_{h}=-\rho C_{p} K_{h}\left(\frac{\partial T}{\partial z}\right)
$$

where the specific heat $C p=9940 \mathrm{j} / \mathrm{kg} \mathrm{c}^{\mathrm{o}}$, and the coefficient of heat diffusivity $K_{h}=1 \times 10^{-4} \mathrm{~m}^{-2} \mathrm{~s}^{-1}[11]$.

The heat flux was directed downwards for all seasons as energy flowed from the warmer upper layers, heated by solar radiation, to the deeper cooler layers. The seasonal vertically averaged magnitude of DHF ranged from a low of -1.6 X $10^{-5}$ $\mathrm{m}^{-2} \mathrm{~s}^{-1}$ attained at station $\mathrm{B}$ during spring to a maximum of $1.1 \times 10^{-2} \mathrm{~m}^{-2} \mathrm{~s}^{-1}$ attained at station during summer. Profiles of seasonally averaged estimates of DHF are depicted in figures (9-16), and its basic statistics are presented in table 2.

The seasonally averages of DHF showed no clear dependence on the water depth, however, the deeper layers $(z>150 \mathrm{~m})$ at station A exhibited less magnitudes of vertical transport of heat. Also, a sharp vertical gradient of temperature existed around the subsurface layer $(30 \mathrm{~m}<\mathrm{z}<$ $75 \mathrm{~m})$.

Table 2. Seasonal vertically averaged estimates of diffusive heat flux $\left(\mathrm{W} \mathrm{m}^{-2}\right)$.

\begin{tabular}{llllll}
\hline & & spring & summer & autumn & winter \\
\hline \multirow{2}{*}{ Min } & St. A $(400 \mathrm{~m})$ & $-5.4 \mathrm{E}-04$ & $-1.1 \mathrm{E}-02$ & $-1.3 \mathrm{E}-02$ & $-5.0 \mathrm{E}-03$ \\
& St. B $(100 \mathrm{~m})$ & $-2.8 \mathrm{E}-04$ & $-8.9 \mathrm{E}-03$ & $-1.2 \mathrm{E}-02$ & $-6.7 \mathrm{E}-03$ \\
\multirow{2}{*}{ Max } & St. A $(400 \mathrm{~m})$ & $-4.1 \mathrm{E}-05$ & $-3.2 \mathrm{E}-04$ & $-4.0 \mathrm{E}-05$ & $4.0 \mathrm{E}-05$ \\
& St. B $(100 \mathrm{~m})$ & $-1.6 \mathrm{E}-05$ & $-1.1 \mathrm{E}-03$ & $-1.6 \mathrm{E}-03$ & $4.0 \mathrm{E}-05$ \\
\multirow{2}{*}{ Mean } & St. A $(400 \mathrm{~m})$ & $-2.7 \mathrm{E}-04$ & $-2.3 \mathrm{E}-03$ & $-2.0 \mathrm{E}-03$ & $-1.0 \mathrm{E}-03$ \\
& St. B $(100 \mathrm{~m})$ & $-7.5 \mathrm{E}-05$ & $-4.4 \mathrm{E}-03$ & $-4.2 \mathrm{E}-03$ & $-1.4 \mathrm{E}-03$ \\
\hline
\end{tabular}

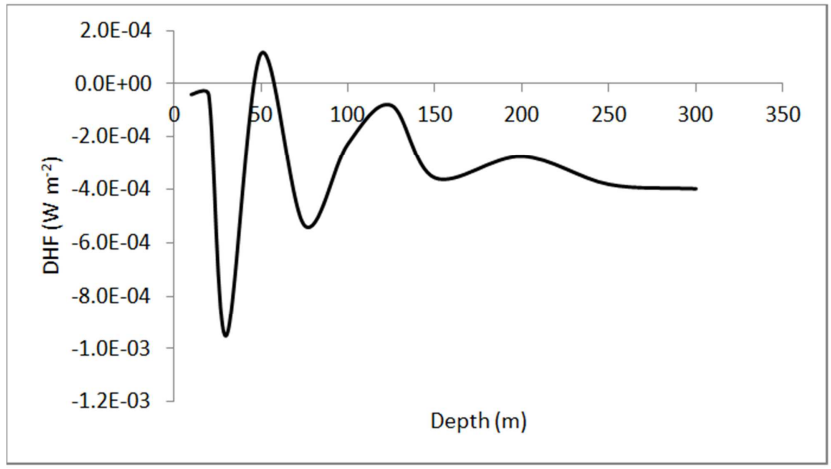

Fig. 9. Vertical distribution of heat flux during spring at station A.

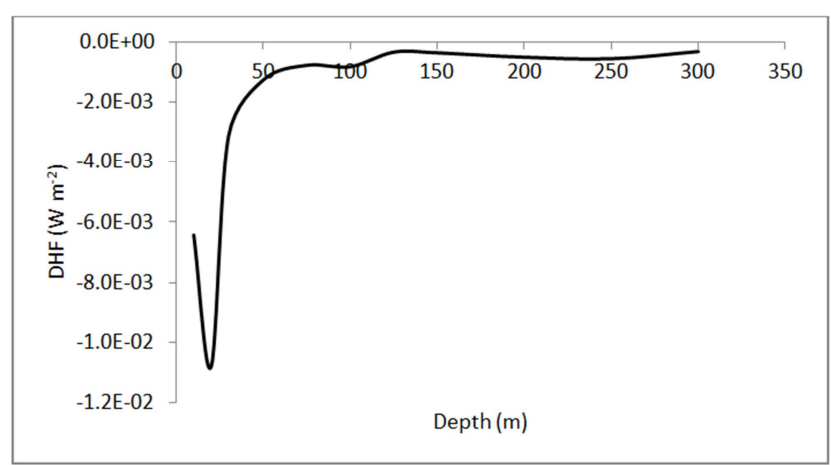

Fig. 10. Vertical distribution of heat flux during summer at station A.

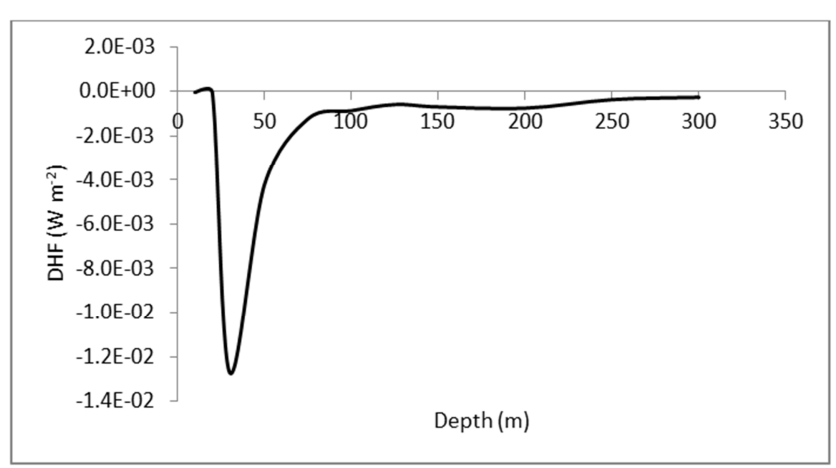

Fig. 11. Vertical distribution of heat flux during autumn at station A. 


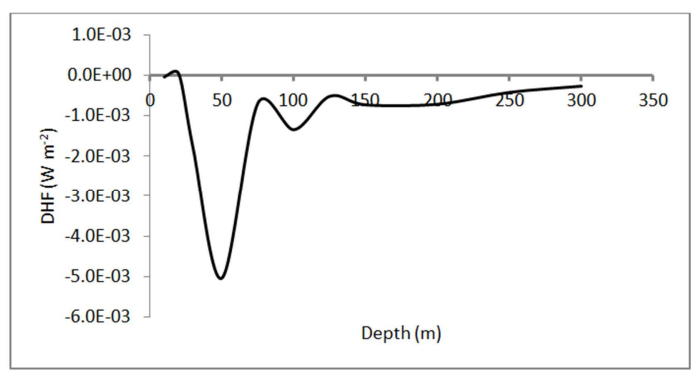

Fig. 12. Vertical distribution of heat flux during winter at station A.

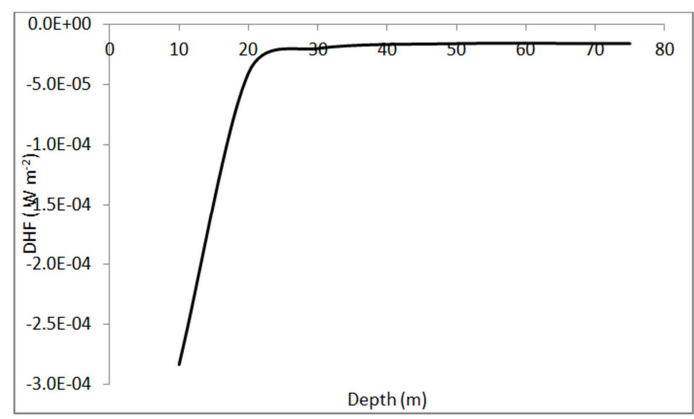

Fig. 13. Vertical distribution of heat flux during spring at station B.

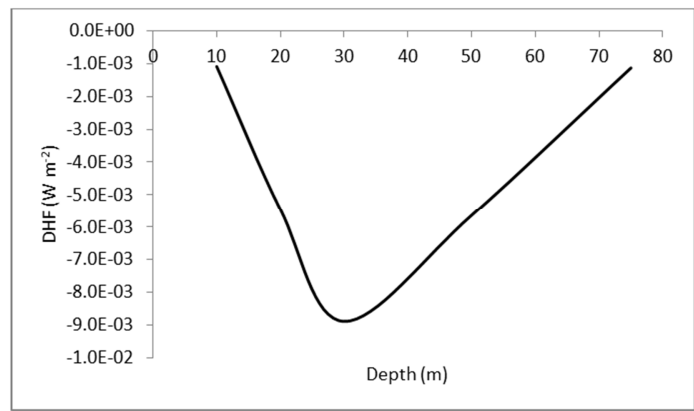

Fig. 14. Vertical distribution of heat flux during summer at station B.

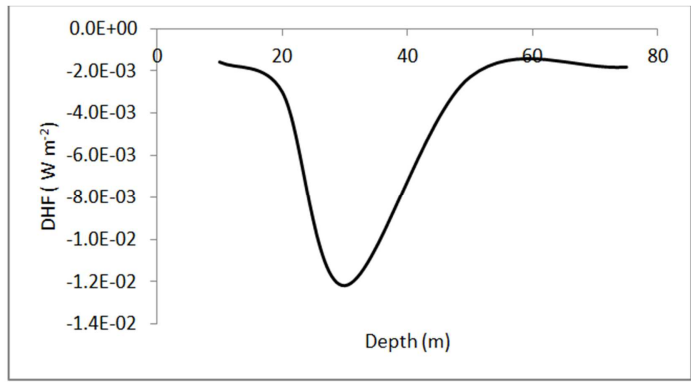

Fig. 15. Vertical distribution of heat flux during autumn at station B.

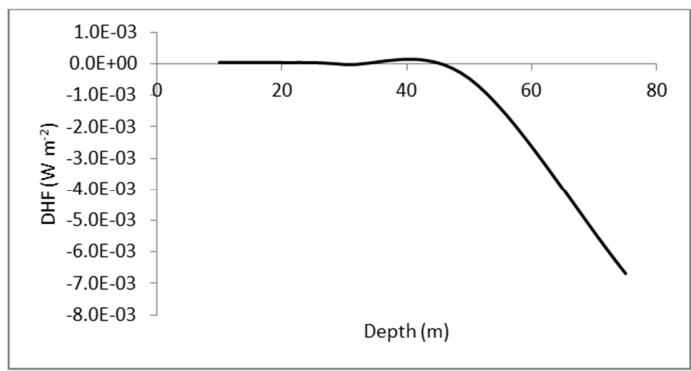

Fig. 16. Vertical distribution of heat flux during winter at station B.

\section{Discussions and Conclusions}

Salt and heat exchange between surface and sub-surface water masses is a complex physical phenomenon which is affected by several geophysical factors as evaporation. Evaporation tends to increase the salinity of the upper layers, thus strengthening the process of salt diffusion. Precipitation has a contrary effect and both evaporation/precipitation are governed by the prevailing meteorological conditions. The circulatory pattern of water masses has also a dominant effect on vertical diffusion of salt and heat.

Generally, the seasonal averaged estimates of DSF were negative, i.e., a downward salt flux occurred in the water column, however, positive estimates of DSF intermittently occurred in the sub surface layer of depth between $75 \mathrm{~m}-150$ $\mathrm{m}$. Vertical diffusion of heat for the four seasons was directed downwards throughout the whole water column, i.e., negative magnitudes of DHF were attained as heat transported vertically by diffusion from warm upper layers to cooler deeper layers.

\section{Acknowledgement}

The author wishes to express his gratitude and appreciation to the NIOF, and Alexandria University for providing the scientific material and research facilities.

\section{References}

[1] G. C. Johnson, "Stress on the Mediterranean outflow plume: Part II. Turbulent dissipation and shear measurements". J. Phys. Oceanogr. 24 (10): 2084-2092, 1996.

[2] T. R. Osborn, "Estimates of the local rate of vertical diffusion from dissipation measurements", J. Phys. Oceanogr. 10: 8389, 1980.

[3] W. Munka and, C. Wunschb, "Abyssal Recipes II: Energetics of tidal and wind mixing". Deep sea research, Part I: 45 (12): 1977-2010, 1998.

[4] S. Kobayashia, J. H. Simpson, T. Fujiwarab, and K. J. Porburghe, "Tidal stirring and its impact on water column stability and property distribution in a semi enclosed shelf sea (Seto Island, Japan)". Continental shelf Res. 26 (11): 12951306,2006

[5] E. P. Hornea, J. W. Lodera, C. E. Naimeb and N. S. Oakeyb, "Turbulent dissipation rates and nitrate supply in the upper water column on Georges Bank, Canada". Deep sea Res. Part II. Topical studies in Oceanography, 43 (7-8): 1683-1712, 1996.

[6] L. N. Ly, W. Roland and Jr. Garwood, "Numerical modeling of wave-enhanced turbulence in the oceanic upper layer. J. Oceanography, Vol. 56, pp. 473-483, 2000.

[7] S. H. Sharaf El Din, F. M. Eid, N. N. Saad, K. A. Alam El Din and M. S. Elsharkawy. "A numerical study of turbulent mixing parameters at the Nile Delta, north of the Egyptian coast". Inter. J. of Biodiversity and Conservation Vol. 2 (12), pp. 422428, 2010. 
[8] S. H. Sharaf El Din, M. S. Elsharkawy. "Mixing pattern off north eastern Egyptian continental slope". Proc. $15^{\text {th }}$ Inter. Multidisciplinary Scientific Geo-Conferences, SGEM 2015. pp. 659-666, 2015.

[9] H. Peters, "Spatial and temporal variability of turbulent mixing in an estuary", J. Mar. Sci, 57: 805-845, 1999.
[10] T. R. Osborn "Estimates of the local rate of vertical diffusion from dissipation measurements". J. Phys. Oceanogr. 10: 83$89,1980$.

[11] R. L. Molinari, J. Swallow and J. F. Festa, "Evolution of the near surface thermal structure in the western Indian Ocean during FGGE, 1979". J. Mar. Sci. 44: 739-762, 1986. 